\title{
The Latest Progress of the Conceptual Framework
}

\author{
Ting Shang \\ Management School, Jinan University, Guangzhou, China \\ Email: 389028632@qq.com
}

Received 20 May 2015; accepted 9 June 2015; published 15 June 2015

Copyright (C) 2015 by author and Scientific Research Publishing Inc.

This work is licensed under the Creative Commons Attribution International License (CC BY). http://creativecommons.org/licenses/by/4.0/

c) (i) Open Access

\begin{abstract}
During the past 30 years, the world's economy developed rapidly, but the formulation of accounting standards often could not keep up with the pace of economic development as the continuous innovation of financial instruments or derivatives financial instruments, the increasingly frequency of unconventional activities such as merger, acquisition and restructuring, the rapid flowing of global capital, and the development of networking, information science and technology. Thus the lagging and patching method of accounting standards made the conceptual framework which was ever explored in the past back to the IASB agenda again. This paper mainly described the latest progress of the conceptual framework after IASB released Discussion Paper, analyzed the characteristics of the restatement of $\mathrm{CF}$, and proposed several thoughts for the China CF and accounting standards.
\end{abstract}

\section{Keywords}

\section{Conceptual Framework, Discussion Paper of CF, Tentative Conclusions of Exposure Draft of CF}

\section{Introduction}

In July 2013 IASB released the Discussion Paper (DP) of A Review of the Conceptual Framework for Financial Reporting, respected to receive feedback opinions about the main part of the CF study [1]. At the end of 24 February 2014 IASB had received 221 comment letters. The IASB then carried out a series of meetings to discuss the following Exposure Draft (ED). Meanwhile, the IASB consulted to some professional groups such as ASAF, IFRS Advisory Council for all the opinions in the comment letter and suggestions for the ED. IASB expected to complete the due process of all the parts in the CF at the end of 2015, and released the final restatement CF. Thus, under this international background, it is beneficial for us to study the latest progress of CF and think about our Chinese CF and accounting standards by reference to the restatement CF. 


\section{Latest Progress}

\subsection{Amendment of Definitions of Assets and Liabilities}

The existing definition of assets and liabilities mainly emphasize the future economic benefits, which made assets and liabilities lose their essential characteristic of resource. Besides, the existing recognition criteria of assets and liabilities set a threshold (50\% probability in practice) for the future cash flow. In this situation, those items that wouldn't produce or produce little future cash flow, but beneficiary for providing useful financial information, couldn't be recognized as assets or liabilities. Thus, the DP removed the expected future economic inflow or outflow from the definition, removed the probability threshold from the recognition criteria (if the existence of certain item does has great uncertainty, it is due to raise resolve solutions when revising or developing IFRS), and added the definition of economic resources (an economic resource is a right, or other source of val$u$, that is capable of producing economic benefits).

On 21 May 2014 the IASB's tentative conclusion after discussion were as following [2]:

1) Assets should be viewed as rights, or bundles of rights, rather than underlying physical or other objects. The IASB noted that in many cases an entity would account for an entire bundle of rights as a single asset, and describe that asset as the underlying object.

2) The reference to future economic benefits should be placed in a supporting definition (of an economic resource), rather than in the definitions of an asset and of a liability.

3) The definition of an economic resource should not include the notion of 'other source of value' that was suggested in the Discussion Paper.

On 21 January 2015 the IASB decided to replace the term "is capable of" with the term "has the potential to" in the definition of an economic resource, and finally define an economic resource as "An economic resource is a right that has the potential to produce economic benefits". Beyond that, IASB decided to revise the definition of Income and Expense, namely also delete the term "future economic benefits".

\subsection{Additional Guidance to Support the Asset and Liability Definitions}

Based on the preliminary views in the DP, 19 June 2014 the IASB decided that the Conceptual Framework should include concepts explaining the nature of the assets and liabilities in executory contracts:

1) An enforceable executory contract contains a right and an obligation to exchange economic resources. The combined right and obligation would constitute a single asset or liability;

2) If an entity enters into a forward contract to purchase a resource at a future date, the entity's asset is normally its right to buy the underlying resource, not the underlying resource itself. However, in some circumstances the terms of a forward contract to purchase a resource may give the purchaser control of that resource. In such circumstances, the purchaser should identify both an asset and a liability. In these circumstances, the contract is not executory: the seller has substantively performed its obligations.

On 24 July 2014 IASB discussed the meaning of present obligation, and decided that if meets the following two points, the present obligation to transfer economic resources resulted by past events could be recognized:

1) The entity has no practical ability to avoid the transfer of economic resources;

2) The amount of the transfer is determined by the benefits that the entity has received, or activities that it has conducted, in the past [2].

\subsection{Recognition and De-Recognition}

On 21 May 2014 the IASB decided that the CF should not establish criteria that govern the recognition of an asset or liability in all circumstances. Instead the CF should describe factors to consider in deciding whether to recognize an asset or liability. However, on 21 January 2015 the IASB decided to describe relevance, faithful representation and the cost benefit constraint as criteria for recognition rather than as factors to consider when deciding whether to recognize an asset or liability.

For de-recognition of assets and liabilities, IASB discussed and decided that the CF should describe the available approaches and factors to consider when certain standard dealing with this issue. There are two aspects to describe [2]:

1) How best to portray the changes that result from a transaction in which an entity retains only a component of an asset or a liability, by either full de-recognition, partial de-recognition, or continued recognition; 
2) How to account for modifications of contracts.

\subsection{Distinction between Liability and Equity Elements}

On 24 April 2014 the IASB tentatively decided that the Conceptual Framework [2]:

1) Should keep the existing binary distinction of liabilities and equity and build on the feedback received on the Discussion Paper to develop definitions of liabilities and equity;

2) Should not provide detailed guidance on how to distinguish liabilities from equity instruments.

On 24 September 2014 the IASB discussed the role of the definitions of a liability and of equity in distinguishing liabilities from equity claims and tentatively decided not to amend those definitions at this time. The IASB also tentatively decided that the CF should neither require nor preclude any accounting requirements for classes of claims within equity.

\subsection{Measurement Attributes}

In the DP of the CF, IASB proposed mixed measurement approach, discussed how Qualitative Characteristics affect measurement, and detailed discussed how particular types of assets and liabilities contribute to future cash flows. However, the comment letters state that this part in the DP was insufficiently developed and has too much Standards-level detail. Thus, IASB describes different measurement bases and information they provide and describes factors to consider in selecting a measurement basis. The comparison between preliminary view in DP and tentative conclusion in ED was listed as Table 1.

\subsection{Presentation in Other Comprehensive Income (OCI)}

To clarify the changes from the preliminary view in DP and tentative conclusion in ED, paper shows the comparison in Table 2.

\section{Characteristics of the Restatement of CF}

As the restriction of the length of the paper, part 2 of this paper chooses several main changes in tentative conclusions of ED. After deeply analyzed the latest progress of CF, this paper concludes several characteristics about the restatement of the CF.

Table 1. Measurement attributes classification in DP and ED.

\begin{tabular}{lll}
\multicolumn{1}{c}{ DP } & & ED \\
\hline Measurement Bases: & Measurement Bases: & \\
- Cost-based measurements & $\bullet$ Historical cost \\
- Current market prices & $\bullet \quad$ Current value \\
\hline
\end{tabular}

Table 2. Presentation in other comprehensive income [2].

\begin{tabular}{|c|c|}
\hline DP & ED \\
\hline $\begin{array}{l}\text { Requires profit or loss as a total } \\
\text { or subtotal }\end{array}$ & $\begin{array}{l}\text { - Including income and expense in profit or loss is classification } \\
\text { - Describes profit or loss as the primary, but not the only, source of information about } \\
\text { an entity's performance } \\
\text { - Includes rebuttable presumption that income and expenses are included in profit or loss } \\
\text { Requires profit or loss as a total or subtotal }\end{array}$ \\
\hline $\begin{array}{l}\text { Describe the types of items that } \\
\text { could be included in OCI }\end{array}$ & $\begin{array}{l}\text { - The IASB could include income and expense in OCI only in limited circumstances: } \\
\text { - Only when that enhances relevance of profit or loss for the period; and } \\
\text { - Only income and expense from changes in current measures of assets and liabilities }\end{array}$ \\
\hline - $\quad$ Recycle in some or all cases & $\begin{array}{l}\text { - Rebuttable presumption that income and expense included in OCI in one period } \\
\text { are subsequently included in profit or loss } \\
\text { - If no meaningful basis for identifying such a subsequent period } \rightarrow \text { an indication } \\
\text { that income and expense should not be included in OCI }\end{array}$ \\
\hline
\end{tabular}




\subsection{Strengthen the Adaptability of the CF to Environmental Changes}

The prosperity and development of the capital market, the comprehensive application of the fair value, produced a series of new economic transactions and events, and also brings the problem of accounting recognition and measurement. How to accurately measure and recognize new transactions and events? This would need the CF revising the relevant theoretical concepts according to the practice.

For example, the extension definition of accounting elements should incorporate those new business transactions, which are difference from the traditional business form, into the category of accounting recognition. The DP and ED tentative conclusions adjusted the definition of assets and liabilities back to 'economic resources', expanded the extension of the definition, eliminated the inconsistency between the current assets (liabilities) definition and some hedging instrument which were recognized within the financial statement. At the same time, once defined assets as economic resources, then the brand, human resources, et al. in practice could be incorporated into the entity's financial statements as the continuous innovation of the measurement methods, which can improve and enhance the quality of the financial statements.

Besides, in current market trading activities, the "one year quality warranty", "3 year repair warranty" soft service means a lot to promote the sales of the enterprise. And also the sale binding after-sale service business model (e.g. elevator sales binding maintenance service) is becoming more and more universal. In this circumstance, the new types of economic activities make it difficult to accurately recognize the timing and amount of revenue using the existing revenue recognition criteria. Thus, the CF should develop corresponding revenue recognition concepts and bases so as to be compatible with the new revenue recognition criteria, which was released by IASB and FASB on 28 May 2014.

In addition, the announcement of SFAC No. 7 [3] that FASB issued in 2000 is an obvious evidence of the CF's adaptation to environmental changes. For the financial instruments, which couldn't obtain the active market price and achieve the fair value through present value technique, the SFAC No. 7 provides theory basis for this method, as well as the "third level estimation" which was mentioned in FAS 157 (year 2006) [4]. From above situation, we can find the dynamic adaptation process between the CF and environmental changes in each other. The change of environment will cause the adjustment of the CF, on the country, the adjusted CF could be used to guide practice work, and then the application of adjusted CF in practice would give feedback to revise CF again.

\subsection{Simplify the Complicated Accounting Rules}

The essence role of CF or accounting standards is to guide practice work, but some complicated accounting rules often made it difficult for practitioners to accurately understand the connotation of the standard and applied it into work. Such as the complicated hedging accounting, four types of financial assets classification in IAS 39 [5], and the treatment of profit and loss of financial assets etc. To follow the "principles-based" request when developing standards, the CF also tries to pursue the basic theoretical guidance rather than large amount of description and illustration. The DP stated in many parts that the CF just elaborated for the basic theory, some special issues shall be stipulated in certain standards.

In November 2008, IASB announced IFRS No. 9 financial instruments. Because of the abuse of financial instruments in practice and the impact of the financial crisis, IASB changed the former four types classification of financial instruments into two big types-classification of financial instruments, aims to form a new, principlebased, more simplified financial reporting standards for financial instruments. Though reduced classes of the financial assets, the standard emphasized that, whether to use the amortized cost or fair value attribute, the principle of providing reliable information for the report user evaluating the time, amount and uncertainty of future cash flow of the entity is must be met.

From the guidance for the recognition and de-recognition of assets and liabilities, and the simplification of measurement bases in the DP, we could see that the CF attempts to simplify the complex rules, and only establish guiding principles. CF is not specific accounting standards, do not need to consider all kinds of special circumstances in reality, it just needs to establish a principle framework, which is reasonable, adaptable to the reality, for accounting standards, and then filling and elaborating when developing certain standards according to practice.

\subsection{Unchanged Effective Parts to Ensure Consistency}

The restatement CF retains several parts of the existing CF, such as capital remaining, chapter 1 and chapter 3 of 
joint conceptual framework project [6]. Although there are many defects about the current conceptual framework, which could not adapt to changes of the environment, the contents of the current conceptual framework is also condenses all the efforts and the accumulation of practical experience for a long time. Therefore, the adjustment of the CF should set priorities, improve contents those can't guide the practical work firstly, and retain other contents without confliction with real situation, to ensure the coherence and consistency of the CF before and after restatement.

\section{Line of Thinking for China CF}

Our country's Basic Standards are issued in the form of law. The content is simple and does not clearly clarify the logical relationship between various provisions, and is really difficult to have guidelines for developing new standards or seeking decisions for practical problems. Besides, the newly revised Accounting Standards in 2014 [7] has made no big change, and does not absorb the new, adaptable ideas listed in the DP and ED of CF. In this paper, the author thinks that the "Basic Standards" still cannot serve as the CF of China, and cannot really reflect the nature and function of conceptual framework. We should set up a set of financial accounting conceptual framework of our own.

In view of the revision of the new conceptual framework by IASB, other countries in the world at present stage also pay great attention to the revised schedule and content of restatement CF. Thus, taking this beneficiary opportunity and time, we should positively think about how to establish our country's own financial accounting CF. I suggest that we could consider from the following aspects:

1) Absorption ideas from the DP and ED of CF

The overall economic environment, the new type business activities, the rapid capital flow etc. in China are much like western countries. Thus, it would be beneficial and less costly to absorb creative and adaptable ideas mentioned in the DP and ED of CF issued by IASB.

For example, our newly revised "Basic Standards" in 2014 don't revise the definition of assets and liabilities, but the existing definitions indeed have many defects and don't adapt to reality facts. The existing definitions mainly concentrate on "future economic benefits", but the chosen measurement attribute is historical measurement basis. This would be confusing to mix the future economic benefits with historical measurement in one definition.

2) International convergence of accounting standards

The IASB has begun to vigorously promote the convergence of international accounting standards since 2001, and then our country also took positive efforts to develop work of international convergence. In addition, as our country's economic strength increases gradually, foreign capital injection, overseas investment, mergers and acquisitions, or assets restructuring and other new business activities occur frequently; the convergence of international accounting standards seems to be more important. Our newly revised Accounting Standards in 2014 have also been revised based on the reason of foreign investment, the reform of property right, the integration of global capital and so on. So when we establish our own CF, we should also consider the convergence with the IASB conceptual framework, so as to reduce friction in the international economic trading or the obstruction in financial statements preparing.

3) Considering China's national conditions and characteristics

In June 2001, FASB issued FAS 141 "Business Combination" [8], officially announced to cancel pooling of interest method, and adopted the purchase method as the only way of preparing consolidated statements. But as state-owned or government involvement enterprises occupy larger proportion in the national economy, our country still retain the pooling of interest methods, which can be divided into two methods, "same control" and "not-same control". Therefore, when we establish our own CF, we should consider how to retain Chinese special national conditions, and at the same time keep convergence with international standards.

\section{Conclusion}

From the description of the latest progress and restatement characteristics of CF, we could see that the CF is not a one-size-fits-all framework, and it should adjust and restate as the environment changes. Even if the restatement CF will be completed in 2016, the CF will continue to adjust and restate in the future so as to adapt to the changing environment and balance the interests of the related parties. In turn, the CF after restatement could continue to influence the development of accounting standards, and then affect the application of accounting 
standards in practice. Thus, we should keep an eye to every restatement of the CF and its influence to accounting standards and practice. From that, we could absorb new ideas and use them in our China CF and accounting rules.

\section{References}

[1] IASB (2013) A Review of the Conceptual Framework for Financial Reporting. IASB, London.

[2] IASB (2015) Effect of Board Re-Deliberations on DP. A Review of the Conceptual Framework for Financial Reporting. IASB, London.

http://www.ifrs.org/Current-Projects/IASB-Projects/Conceptual-Framework/Documents/Effect-of-Board-decisions-onDP-January-2015.pdf

[3] FASB (2000) SFAC No. 7: Using Cash Flow Information and Present Value in Accounting Measurements. FASB, Connecticut.

[4] FASB (2006) FAS 157: Fair Value Measurement.

[5] IASB (1999) IAS 39: Financial Instruments: Recognition and Measurement. IASB, London.

[6] FASB (2010) SFAC No. 8: Conceptual Framework for Financial Reporting. Chapter 1, The Objective of General Purpose Financial Reporting, and Chapter 3, Qualitative Characteristics of Useful Financial Information. FASB, Connecticut.

[7] Ministry of Finance of the People’s Republic of China (2014) Corporate Accounting Standards. Ministry of Finance of the People's Republic of China, Beijing.

[8] FASB (2001) FAS 141: Business Combination. FASB, Connecticut. 